\title{
Analysis of blood donor pre-donation deferral in Dubai: characteristics and reasons
}

\author{
This article was published in the following Dove Press journal: \\ Journal of Blood Medicine \\ 25 May 2017 \\ Number of times this article has been viewed
}

\author{
Laila Al Shaer' \\ Ranjita Sharma ${ }^{2}$ \\ Mahera AbdulRahman² \\ 'College of Medicine, Mohammed Bin \\ Rashid University of Medicine and \\ Health Sciences, Dubai, UAE; ${ }^{2}$ Dubai \\ Health Authority, Dubai, UAE
}

\begin{abstract}
Background: To ensure an adequate and safe blood supply, it is crucial to select suitable donors according to stringent eligibility criteria. Understanding the reasons for donor deferral can help in planning more efficient recruitment strategies and evaluating donor selection criteria. This study aims to define donor pre-donation deferral rates, causes of deferral, and characteristics of deferred donors in Dubai.
\end{abstract}

Materials and methods: This retrospective study was conducted on all donors who presented for allogeneic blood donation between January 1, 2010, until June 30, 2013, in Dubai Blood Donation Centre, accredited by the American Association of Blood Banks. The donation and deferral data were analyzed to determine the demographic characteristics of accepted and deferred donors, and frequency analyses were also conducted.

Results: Among 142,431 individuals presenting during the study period, 114,827 (80.6\%) were accepted for donation, and 27,604 (19.4\%) were deferred. The overall proportion of deferrals was higher among individuals less than 21 years old $(35 \%, P<0.000)$, females $(44 \%$ were deferred compared to $15 \%$ of males, $P<0.0001)$, and first-time donors $(22 \%$ were deferred vs $14 \%$ of repeat donors, $P<0.0001)$. The main causes for a temporary deferral were low hemoglobin and high blood pressure.

Discussion: The deferral rate among blood donors in Dubai is relatively high compared to the internationally reported rates. This rate was higher among first-time donors and females, with low hemoglobin as the major factor leading to a temporary deferral of donors. Strategies to mitigate deferral and improve blood donor retention are urged in Dubai to avoid additional stress on the blood supply.

Keywords: blood donation, blood safety, donor deferral, selection criteria

\section{Introduction}

Blood safety is a major concern all over the world, and blood donor selection and screening is one of the most important steps used to ensure blood safety. ${ }^{1,2}$ Though the demand for blood is decreasing in many countries, due to preoperative blood management, the demand for blood is constantly increasing in United Arab Emirates (UAE) due to the remarkable increase in population and high prevalence of hemoglobinopathies in the country; this mandates recruiting safe donors and prohibiting high-risk donors from donation. In spite of the importance of blood donor selection for blood safety, we need to consider that selection processes might have negative impacts on the blood supply, as many deferred donors might not return to donate again due to negative feelings resulting from their deferral. ${ }^{3,4}$ Hence, it is crucial to define a rational, evidence-based donor selection process and eliminate practices that lead to the unnecessary deferral of volunteered donors. ${ }^{5,6}$
Correspondence: Laila Al Shaer

Mohammed Bin Rashid University of

Medicine and Health Sciences, College of

Medicine, P.O. Box: 505055, Dubai, UAE

Tel +97l 43838708

Email laila.alsuwaidi@mbru.ac.ae 
In 2013, the UAE recorded a blood collection rate of 11.4 whole blood units per 1,000 inhabitants, with 19.8 whole blood units per 1,000 inhabitants in the city of Dubai. The national program for donor deferral in the UAE is based on the World Health Organization recommendations and complies with the American Association of Blood Banks (formerly AABB) standards. Blood donor centers in the UAE are dependent on volunteer blood donors, and all prospective blood donors must undergo a pre-donation health screening to determine their eligibility to donate blood. During the screening process, a detailed medical history is taken via a Donor History Questionnaire, and a physical examination is performed, during which weight, pulse, blood pressure, and temperature measurements are taken and hemoglobin levels are determined. Prospective donors who do not meet the criteria for donation are designated as deferred pre-donation.

The pre-donation deferral rate in the Middle East has been reported to vary from $19.2 \%$ in Saudi Arabia to $30.9 \%$ in parts of Iran. ${ }^{7,8}$ In the UAE, little is known about donor deferral, characteristics of deferred donors, and the rates of pre-donation deferral. The aim of the study is to describe pre-donation donor deferral and the approaches to deferral in Dubai, a city where the collected blood donations account for approximately $40 \%$ of the total donations in the UAE, to appreciate the role that deferrals play in transfusion safety. This might also help in designing more efficient recruitment strategies. UAE has high prevalence of thalassemia major, which demands regular and urgent blood supplies. ${ }^{9}$ Thus, the collection process and donor selection in Dubai need to be analyzed to avoid putting additional restrictions on the limited blood supply.

The objective of this study was to assess the frequency and reasons for donor deferral prior to the blood donation process so that temporarily deferred donors with correctable conditions could be recognized, appropriately educated, and guided to eligibly prepare them for future donation as well as to maintain continuous blood supply. To our knowledge, this is the first detailed analysis to report the pre-donation deferral rate and reasons for deferral in the blood donor population in the UAE.

\section{Materials and methods}

Dubai is one of the seven emirates of the UAE and has a population of nearly 2.2 million (as of 2013). Dubai's population is estimated to be 2.2 million, with two-thirds of the population falling between the ages of 20 and 39. Approximately $75 \%$ of Dubai's residents are males $(1,677,330$ males vs 536,515 females). ${ }^{10}$ The Dubai Blood Donation Centre (DBDC) in the Dubai Health Authority is the major local supplier of blood and blood components for most of the governmental and private hospitals in the country. The DBDC collects and processes an average of 43,000 units of blood per year, covering $100 \%$ of the blood needs of the city of Dubai.

\section{Overall study design}

We conducted this retrospective study on volunteer donors aged 17-65 years who presented for blood donation between January 1, 2010, until June 30, 2013. The data set was restricted to allogeneic whole blood donations and included 142,431 prospective blood donations obtained from the donor database of the DBDC. Analyses were focused on deferrals based on vital signs and donor health interview. The data were retrieved from both first-time and repeat donors (eg, those who made at least two donations within past 2 years). This study does not address individuals who were self-deferred.

Ethical approval was obtained from the Medical Research Committee of the Dubai Health Authority (Reference: MRC10/2012_05). The committee operates in accordance with the International Conference on Harmonisation's/Good Clinincal Practice (ICH/GCP) guidelines.

\section{Measures}

Blood transfusions and donations are regulated by the Federal Government of the UAE and the UAE Supreme National Blood Transfusion Committee. Both regulatory bodies are in line with the international standards of the AABB that defines the specific requirements for donor recruitment and deferral criteria. In the pre-donation assessment, each blood donor is interviewed face-to-face and checked for vital signs (blood pressure and pulse), weight, and hemoglobin $(\mathrm{Hb})$ level, which is measured using finger prick sample (Hemocue 201+, Hemocue, Inc., Mission Viejo, CA, USA).

Upon completion of the interview and review of the donor responses, the prospective donor is either declared fit to donate blood or alternatively deemed ineligible and deferred from blood donation. The criteria for donor deferral are shown in Table S1. For our analysis, the reasons for deferral were categorized into seven groups (Table 1). As per policy in Dubai health authority, deferred donors are referred to a health-care professional for further evaluation.

\section{Statistical analysis}

Data were electronically retrieved from the DBDC database and were merged into a new data set. All personal identifiers 
Table I Reasons for deferral: numbers and rates (per 10,000 donations) of deferred visits by first-time and repeat donors from January 2010 to June 2013

\begin{tabular}{|c|c|c|c|c|}
\hline Deferral category & First-time (rate) & Repeat (rate) & Missing (rate) & Total (rate) \\
\hline Low $\mathrm{Hb}$ & $9,582(673)$ & $3,177(223)$ & $468(33)$ & I3,227 (929) \\
\hline High blood pressure & $2,263(159)$ & $87 I(6 I)$ & $32(2)$ & $3,166(222)$ \\
\hline Medical diagnosis/medication ${ }^{a}$ & $1,684(118)$ & $492(35)$ & $0(0)$ & $2,176(153)$ \\
\hline Fever/flu/cough & $1,440(101)$ & $418(29)$ & $40(3)$ & $\mathrm{I}, 898(133)$ \\
\hline High-risk donor ${ }^{\mathrm{b}}$ & $388(27)$ & $\mathrm{I}, 309(92)$ & $24(2)$ & $I, 72 I(|2|)$ \\
\hline Infectious exposure ${ }^{c}$ & $655(46)$ & $147(10)$ & $0(0)$ & $802(56)$ \\
\hline Other ${ }^{d}$ & $3,262(229)$ & $\mathrm{I}, 032(72)$ & $320(22)$ & $4,614(324)$ \\
\hline Total number of deferred visits & $19,274(1,353)$ & $7,446(523)$ & $884(62)$ & $27,604(1,938)$ \\
\hline
\end{tabular}

Notes: a Medical diagnosis category includes deferrals due to cancer, glucose-6-phosphate dehydrogenase deficiency, surgical procedures, and/or conditions related to cardiac, gastroenterology, neurology, pulmonary, endocrinology, and urology diseases. Medication includes antibiotics. ${ }^{\mathrm{b} D}$ Donors positive for infectious disease markers or at risk for exposure. 'Donor at risk of infectious disease due to exposure to dentist, endoscopy, history of malaria, tuberculosis, typhoid, UK visit, tattoo, and needle prick. Includes other deferral reasons such as blood transfusion, positive antibody screening, pregnancy/abortion, apprehensive/cannot wait, age/weight out of the acceptable range, and/or no identification document, vaccination.

Abbreviation: $\mathrm{Hb}$, hemoglobin.

were removed before analysis. The donation and deferral data were analyzed to determine the demographic characteristics of accepted and deferred donors. Data management and analysis were conducted using computer software (GraphPad Prism 5.0, GraphPad Software, Inc., San Diego, CA, USA). The significance limit was set at 0.05 and $\chi^{2}$ test with Yates correction was used to determine statistical significance.

\section{Results}

During the study period, a total of 142,431 individuals presented for allogeneic blood donation at the DBDC (Table 2). Of those, 114,827 ( $80.6 \%$ of presenting individuals) were accepted for donation, and 27,604 (19.4\%) were deferred. The majority of prospective donors were within the age group of 21-40 years (105,074 individuals; $73.8 \%)$, expatriates hailing from Asia (94,283 individuals; 66\%), male (84\% vs $16 \%$ of female), and repeat donors $(55,021,38.6 \%$ of presenting individuals).

The most common reasons for deferral among the blood donor candidates were low $\mathrm{Hb}$ (929 per 10,000 presentations; Table 1), high blood pressure (222 per 10,000 presentations), medical diagnosis and medication (153 per 10,000 presentations), fever/flu/cough (133 per 10,000 presentations), and high-risk donor (121 per 10,000 presentations). Of the total deferrals, $17 \%(4,614$ out of 27,604$)$ were classified as "other," which indicates that the reason for deferral did not fit in any of the deferral categories used in our study. The deferral was higher in females $(44 \%$ of females were deferred compared to $15 \%$ of males, $P<0.0001)$ and firsttime donors ( $22 \%$ first-time donors were deferred vs $14 \%$ of repeat donors, $P<0.0001)$. The deferral proportions were almost similar across nationalities.
Table 2 Demographic details of all prospective donors who visited from January 2010 to June 2013

\begin{tabular}{|c|c|c|}
\hline Characteristic & Total $^{\mathrm{a}}$ n (\%) & Deferred visits n (\%) \\
\hline Total & $|42,43|$ & $27,604(19.4)$ \\
\hline \multicolumn{3}{|l|}{ Gender } \\
\hline Male & $120,125(84)$ & $|7,70|(15)$ \\
\hline Female & $22,095(16)$ & $9,729(44)$ \\
\hline Missing & $211(0)$ & $174(82)$ \\
\hline \multicolumn{3}{|l|}{ Nationality } \\
\hline Asian & $94,283(66)$ & 17,853 (19) \\
\hline Middle-Eastern & $34,897(24.5)$ & $6,285(18)$ \\
\hline African & $6,833(5)$ & $\mathrm{I}, 432(2 \mathrm{I})$ \\
\hline European & $3,602(2.5)$ & $834(23)$ \\
\hline North American & $1,129(1)$ & $258(23)$ \\
\hline Australian & $454(0)$ & $81(18)$ \\
\hline South American & $|4|(0)$ & $34(24)$ \\
\hline Missing & $1,053(1)$ & $762(72)$ \\
\hline \multicolumn{3}{|l|}{ Age (years) } \\
\hline $17-20$ & $6,208(4.4)$ & 2,144 (35) \\
\hline $21-30$ & $50,262(35.3)$ & 8,549 (17) \\
\hline $31-40$ & $54,812(38.5)$ & $9,348(17)$ \\
\hline $4 I-50$ & $22,934(16.1)$ & $4,442(19)$ \\
\hline $5 I-60$ & $5,728(4)$ & $1,309(23)$ \\
\hline $61-65$ & $592(0.4)$ & $|7|(29)$ \\
\hline Missing & $\mathrm{I}, 895(\mathrm{I} .3)$ & I,64I (87) \\
\hline \multicolumn{3}{|l|}{ Donation history } \\
\hline First Time & $86,413(60.7)$ & $19,274(22)$ \\
\hline Repeat & $55,021(38.6)$ & $7,446(14)$ \\
\hline Missing & $997(0.7)$ & $884(89)$ \\
\hline
\end{tabular}

Note: ${ }^{a}$ Total number of prospective blood donations including the deferrals.

The demographic characteristics of individuals deferred are described in Table 3. Deferrals due to $\mathrm{Hb}$ levels were more frequent in females than males $(P<0.0001)$, and in first-time donors than repeat donors $(P<0.0001)$. Deferral due to blood pressure was more frequent among first-time donors $(P<0.05)$. In addition, first-time donors and males were deferred due to medical diagnosis and medication 
Table 3 Demographic characteristics and rates (per 10,000 prospective donations) of visits deferred due to low Hb, high blood pressure, medical diagnosis/medication, fever/flu, and being a high-risk donor, from January 2010 to June $2013^{\mathrm{a}}$

\begin{tabular}{|c|c|c|c|c|c|c|c|}
\hline $\begin{array}{l}\text { Variable/deferral } \\
\text { reason }\end{array}$ & Low Hb & $\begin{array}{l}\text { High blood } \\
\text { pressure }\end{array}$ & $\begin{array}{l}\text { Medical diagnosis/ } \\
\text { medication }\end{array}$ & $\begin{array}{l}\text { Fever/flul } \\
\text { cough }\end{array}$ & $\begin{array}{l}\text { High-risk } \\
\text { donor }\end{array}$ & $\begin{array}{l}\text { Total } \\
\text { deferrals }\end{array}$ & $\begin{array}{l}\text { Total } \\
\text { visits }\end{array}$ \\
\hline \multicolumn{8}{|l|}{ Gender } \\
\hline Male & $6,305(443)$ & $2,585(I 8 I)$ & I,407 (99) & $\mathrm{I}, 589(\mathrm{I} \mid \mathrm{I})$ & I,532 (108) & $13,4 \mid 8(942)$ & 120,125 \\
\hline Female & $6,854(48 I)$ & $563(40)$ & $294(21)$ & $300(21)$ & $162(11)$ & $8,173(574)$ & 22,095 \\
\hline Missing & $68(5)$ & $18(I)$ & $475(33)$ & $9(1)$ & $27(2)$ & $137(10)$ & 211 \\
\hline \multicolumn{8}{|l|}{ Donation history } \\
\hline First time & $9,582(673)$ & 2,263 (I59) & $\mathrm{I}, 23 \mathrm{I}(86)$ & $\mathrm{I}, 440(\mathrm{I} 0 \mathrm{I})$ & 388 (27) & $14,904(1,046)$ & 86,413 \\
\hline Repeat & 3,177 (223) & $871(6 I)$ & $396(28)$ & $418(29)$ & $1,309(92)$ & $6,171(433)$ & 55,021 \\
\hline Missing & $468(33)$ & $32(2)$ & $89(6)$ & $40(3)$ & $24(2)$ & $653(46)$ & 997 \\
\hline \multicolumn{8}{|l|}{ Age (years) } \\
\hline $17-20$ & I,III3 (78) & $148(10)$ & $68(5)$ & $101(7)$ & $26(2)$ & $\mathrm{I}, 456(102)$ & 6,208 \\
\hline $21-30$ & $4,203(295)$ & $814(57)$ & $526(37)$ & $724(5 \mathrm{I})$ & $426(30)$ & $6,693(470)$ & 50,262 \\
\hline $31-40$ & $4,38 I(308)$ & $\mathrm{I}, 142(80)$ & $654(46)$ & $722(5 \mathrm{I})$ & 691 (49) & $7,590(533)$ & 54,812 \\
\hline $4 I-50$ & 2,039 (143) & $699(49)$ & $282(20)$ & $222(16)$ & $356(25)$ & $3,598(253)$ & 22,934 \\
\hline $5 I-60$ & $575(40)$ & 245 (I7) & $85(6)$ & $44(3)$ & $102(7)$ & I,05। (74) & 5,728 \\
\hline $6 I-65$ & $59(4)$ & $24(2)$ & $14(I)$ & $2(0)$ & $10(1)$ & $109(8)$ & 592 \\
\hline Missing & $857(60)$ & $94(7)$ & $87(6)$ & $83(6)$ & $110(8)$ & $\mathrm{I}, 23 \mathrm{I}(86)$ & 1,895 \\
\hline
\end{tabular}

Note: ${ }^{\mathrm{D} D a t a}$ are reported as number (rate).

Abbreviation: $\mathrm{Hb}$, hemoglobin.

more often than repeat donors $(P<0.0001)$ and female donors $(P<0.0001)$.

Having a fever/flu/cough was the fourth most common reason for deferral in the DBDC; this reason for deferral was more likely to be cited among first-time donors than repeat donors $(P<0.0001)$. Alternatively, deferrals due to being a high-risk donor were more likely in males than females $(P<0.0001)$ and, surprisingly, in repeat donors than first-time donors $(P<0.0001)$.

\section{Discussion}

Transfusion-transmissible infections have made both blood bankers and health authorities overly cautious to obtain a high level of blood product safety. Blood donors have to meet stringent eligibility criteria through questionnaire before donation to ensure blood safety. Donor deferral is a form of rejection and loss of time for both blood donors and blood bank. Therefore, having rational donor recruitment strategies with more substantial criterion, without affecting blood safety, may reduce the number of deferrals.

In this study, we report for the first time an analysis of deferred donors in Dubai, UAE, to add an epidemiologic perspective to donor deferral in the region. The proportion of presenting donors who were deferred in our study concurs with figures reported in neighboring countries such as Saudi Arabia $(19.2 \%)^{7}$ and is even lower than the regionally reported rates of $25.6 \%$ and $30.9 \%$ in Iran. ${ }^{8,9}$ However, the international comparison shows that the deferral rate in this study $(19.4 \%)$ is relatively higher than the rates reported in Germany $(6.2 \%),{ }^{11}$ France $(10.8 \%),{ }^{12}$ USA $(12.8 \%-$ $15.6 \%),{ }^{2,13}$ Japan (14\%), ${ }^{14}$ Singapore (14.4\%), ${ }^{15}$ Turkey $(14.6 \%),{ }^{16}$ India $(5.8 \%-16.4 \%),{ }^{3,4,17-19}$ and Nigeria $(16 \%) .{ }^{20}$ Though the differences in the deferral rates may probably be due to the differences in the donor population or donor selection criteria used, the relatively high rate of donor deferral in DBDC requires further improvements to the donor deferral process to avoid any psychological effects or negative impacts on prospective donors that may prevent them from future donations.

The current study shows that the majority of the donors at Dubai were males and first-time donors, which reflects the domination of the mobile population of expatriate males in the community. The considerable expatriate population in UAE, and in Dubai especially, is due to the increase of investments and job opportunities. Notably, the expat population is dominated by the SouthEast Asian countries, especially India and Pakistan, with majority of the population serving as average workforce in the manufacturing industries. Interestingly, the deferral rates tended to be higher in females and first-time donors, which is similar to deferred candidates worldwide, including those in USA, ${ }^{13}$ India, ${ }^{4,18}$ and Saudi Arabia. ${ }^{7}$

The study also reveals high rates of donor loss due to failure to meet $\mathrm{Hb}$ criteria. This may reflect the origin of the donors, as majority of them are from the Asian continent where the low $\mathrm{Hb}$ is the major cause of deferral. In addition, the possibility of nutritional patterns in the immigrant population affects iron status. Khurram et $\mathrm{al}^{20}$ reported that 
nutritional deficiencies, particularly iron deficiency (anemia), account for $6 \%$ of public health burden in subcontinent regions. The majority of donors with low $\mathrm{Hb}$ were females, and this is in line with other reports worldwide..$^{3,17,22-24}$ Low $\mathrm{Hb}$ has been reported as a major cause of deferral in many studies reported from Turkey, Brazil, Saudi Arabia, Japan, India, and Pakistan; the results of our study is also in line with these reports. ${ }^{6,7,14,19,25}$ We believe that combining anemia prevention measures and treatment in donor recruitment strategies could help regain the donors and developing a healthy blood donor pool. This process will also bring back deferred donors and minimize loss of blood donors and keep them motivated. Further studies focusing on donor $\mathrm{Hb}$ levels are needed to address iron depletion and anemia in prospective blood donors in this region. At the same time, there is a need to explore whether the donors deferred due to $\mathrm{Hb}$ levels are actually anemic or simply have an $\mathrm{Hb}$ level lower than that specified by the donation criteria.

The prevalence of the main transfusion-transmissible viral infections (TTVIs) in the study population were previously described by Al Shaer et al. ${ }^{26}$ The individual prevalences of hepatitis $\mathrm{B}$ virus, hepatitis $\mathrm{C}$ virus, and human immunodeficiency virus per 100,000 donations were 234.4, 110, and 4, respectively. Additionally, incidence rate and estimated residual risk in the previous study indicate that the current risk of TTVIs attributable to blood donation is relatively low in the UAE.

The current study shows that deferrals due to being a high-risk donor were unexpectedly more common in repeat donors than in first-time donors. This highlights the need for further improvements of donor deferral registries and donor notification process in the DBDC to avoid recurring donation attempts among those deferred donors who are not aware of the reason for their deferral. Deferred donors might come back to donate for several reasons: 1) they might not be aware of the reason for deferral or do not understand the request for deferral - this is common among less educated donors such as laborers; 2) they might not accept the need for the deferral, believing that the test result is a false-positive; or 3 ) the donors might be seeking blood testing for TTVIs. ${ }^{27}$

The shortcoming in this study presentation is the study type, which was retrospectively rather than prospectively planned. This limited the ability to add in ferritin measurement to gain real understanding of the deferral due to $\mathrm{Hb}$ level.

There is a need to assess the deferral pattern for recommending revisions in donor selection criteria as well as planning strategies for reentry of donors deferred temporarily to be brought back to regular donor pool. Giving considerable attention to donor awards, education, and appreciation programs would further improve retention of new donors and would build up a wide database of repeat donors. Additionally, paying special attention to young, first-time donors might increase future repeat donations and provide more useable units of blood to help maintain adequate stocks. Temporary deferred donors require proper follow-up and corrective actions management to minimize loss of valuable blood donors.

\section{Acknowledgments}

The authors wish to thank all Dubai Blood Donation Centre staff for their support and cooperation.

\section{Author contributions}

All authors contributed in designing the study, collecting and analyzing data, preparing the draft, and critically reviewing the final manuscript.

\section{Disclosure}

The authors report no conflicts of interest in this work.

\section{References}

1. Zou S, Musavi F, Notari EP, Fujii KE, Dodd RY; ARCNET Study Group. Prevalence of selected viral infections among temporarily deferred donors who returned to donate blood: American Red Cross blood donor study. Transfusion. 2005;45:1593-1600.

2. Zou S, Musavi F, Notari EP, Rios JA, Trouern-Trend J, Fang CT. Donor deferral and resulting donor loss at the American Red Cross blood services, 2001 through 2006. Transfusion. 2008;48:2531-2539.

3. Agnihotri N. Whole blood donor deferral analysis at a center in Western India. Asian J Transfus Sci. 2010;4:116-122.

4. Sundar P, Sangeetha SK, Seema DM, Marimuthu P, Shivanna N. Predonation deferral of blood donors in south Indian set-up: an analysis. Asian J Transfus Sci. 2010;4:112-115.

5. Kouao MD, Dembelé B, N'Goran LK, et al. Reasons for blood donation deferral in sub- Saharan Africa: experience in Ivory Coast. Transfusion. 2012;52:1602-1606.

6. Gonçalez TT, Sabino EC, Schlumpf KS, et al. Analysis of donor deferral at three blood centers in Brazil. Transfusion. 2013;53:531-538.

7. Bashawri L. A review of pre-donation blood donor deferrals in a university hospital. J Family Community Med. 2005;12:1-12.

8. Kasraian L, Negarestani N. Rates and reasons for blood donor deferral, Shiraz, Iran. A retrospective study. Sao Paulo Med J. 2014;128:320-323.

9. Belhoul KM, Abdulrahman M, Alraei RF. Hemoglobinopathy carrier prevalence in the United Arab Emirates: first analysis of the Dubai Health Authority premarital screening program results. Hemoglobin. 2013;37:359-368.

10. Government of Dubai. Population Bulletin Emirate of Dubai 2013. Published February, 2014. Available at: https://www.dsc.gov.ae/Public ation/\%D9\%86\%D8\%B4\%D8\%B1\%D8\%A9\%20\%D8\%A7\%D9\%84 \%D8\%B3\%D9\%83\%D8\%A7\%D9\%86\%202013\%20En.pdf. Accessed May 17, 2017

11. Müller-Steinhardt M, Weidmann C, Wiesneth M, et al. Donor deferral rates after the implementation of a New German blood donor questionnaire. Transfus Med Hemother. 2012;39:17-22. 
12. Lawson-Ayayi S, Salmi LR. Epidemiology of blood collection in France. Eur J Epidemiol. 1999;15:285-292.

13. Shaz BH, James AB, Hillyer KL, Schreiber GB, Hillyer CD. Demographic variations in blood donor deferrals in a major metropolitan area. Transfusion. 2010;50:881-887.

14. Ngoma AM, Goto A, Sawamura Y, Nollet KE, Ohto H, Yasumura S. Analysis of blood donor deferral in Japan: characteristics and reasons. Transfus Apher Sci. 2013;49:655-660.

15. Lim JC, Tien SL, Ong YW. Main causes of pre-donation deferral of prospective blood donors in the Singapore blood transfusion service. Ann Acad Med Singapore. 1993;22:326-331.

16. Gülen H, Tüzün F, Ayhan Y, et al. The evaluation of blood donor deferral causes. Pediatr Hematol Oncol. 2006;23:91-94.

17. Bahadur S, Jain S, Goel RK, Pahuja S, Jain M. Analysis of blood donor deferral characteristics in Delhi, India. Southeast Asian J Trop Med Public Health. 2009;40:1087-1091.

18. Arun R, Subash S, Arumugam P. Analysis of blood donor deferral causes in Chennai, India. Int J Med Health Sci. 2012;3:61-65.

19. Chaudhary RK, Gupta D, Gupta RK. Analysis of donor-deferral pattern in a voluntary blood donor population. Transfus Med. 1995;5:209-212.

20. Ekwere TA, Ino-Ekanem M, Motilewa OO, et al. Pattern of blood donor deferral in a tertiary hospital, south-south, Nigeria: A three-year study review. Int J Blood Transfus Immunohematol. 2014;4:7-13.
21. Khurram S, Borhany M, Anwar N, et al. Frequency and reasons of donor deferral prior to blood donation process: a single centre experience. Transfusion Medicine. 2017:27(1):10-15.

22. Birjandi F, Gharehbaghian A, Delavari A, Rezaie N, Maghsudlu M. Blood donor deferral pattern in Iran. Arch Iran Med. 2013;16: 657-660.

23. Di Lorenzo Oliveira C, Loureiro F, de Bastos MR, Proietti FA, Carneiro-Proietti AB. Blood donor deferral in Minas Gerais State, Brazil: blood centers as sentinels of urban population health. Transfusion. 2009;49:851-857.

24. Charles KS, Hughes P, Gadd R, Bodkyn CJ, Rodriguez M. Evaluation of blood donor deferral causes in the Trinidad and Tobago National blood transfusion service. Transfus Med. 2010;20:11-14.

25. Tufail S, Baber F, Ikram N, Raza M, Abdul-Shakoor H. Blood donors deferral- Causes. J Rawal Med Coll. 2013;17:119-121.

26. Al Shaer L, AbdulRahman M, John TJ, AlHashimi A. Trends in prevalence, incidence, and residual risk of major transfusion-transmissible viral infections in United Arab Emirates blood donors: impact of individual-donation nucleic acid testing, 2004 through 2009. Transfusion. 2012;52:2300-2309.

27. Cable R, Musavi F, Notari E, Zou S; ARCNET Research Group. Limited effectiveness of donor deferral registries for transfusion-transmitted disease markers. Transfusion. 2008:48:34-42.
Journal of Blood Medicine

\section{Publish your work in this journal}

The Journal of Blood Medicine is an international, peer-reviewed, open access, online journal publishing laboratory, experimental and clinical aspects of all aspect pertaining to blood based medicine including but not limited to: Transfusion Medicine; Blood collection, Donor issues, Transmittable diseases, and Blood banking logistics; Immunohematology; Artificial and alternative
Dovepress

blood based therapeutics; Hematology; Biotechnology/nanotechnology of blood related medicine; Legal aspects of blood medicine; Historical perspectives. The manuscript management system is completely online and includes a very quick and fair peer-review system. Visit http://www.dovepress.com/ testimonials.php to read real quotes from published authors. 